\title{
The Use of Marine Ecosystem Metrics for Preseason Forecasts of Salmon Harvest
}

\author{
Andrew Gray ${ }^{1}$, Jim Murphy ${ }^{1}$, Emily Fergusson ${ }^{1}$, Jordan Watson ${ }^{1}$, Edward Farley ${ }^{1}$, and Kathrine Howard ${ }^{2}$

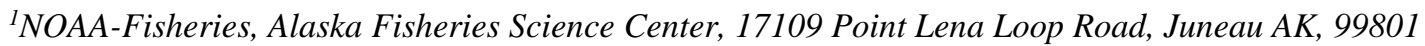 \\ ${ }^{2}$ Alaska Department of Fish and Game, Alaska Department of Fish and Game \\ 333 Raspberry Rd. Anchorage, AK 99518
}

Keywords: Salmon, Forecast, Management

Annual forecasts of pink salmon (Oncorhynchus gorbuscha) harvest in Southeast Alaska (SEAK) and Chinook salmon (Oncorhynchus tshawytscha) returns to the Yukon River were developed to advise fishery managers, members of fishing industries, and the public. Although the forecasts were developed independently for different species and widely separated geographic localities (Fig. 1), the projects illustrate the utility of using marine ecosystem metrics for forecasting future harvests of salmon and how to effectively communicate results and uncertainty to stakeholders.

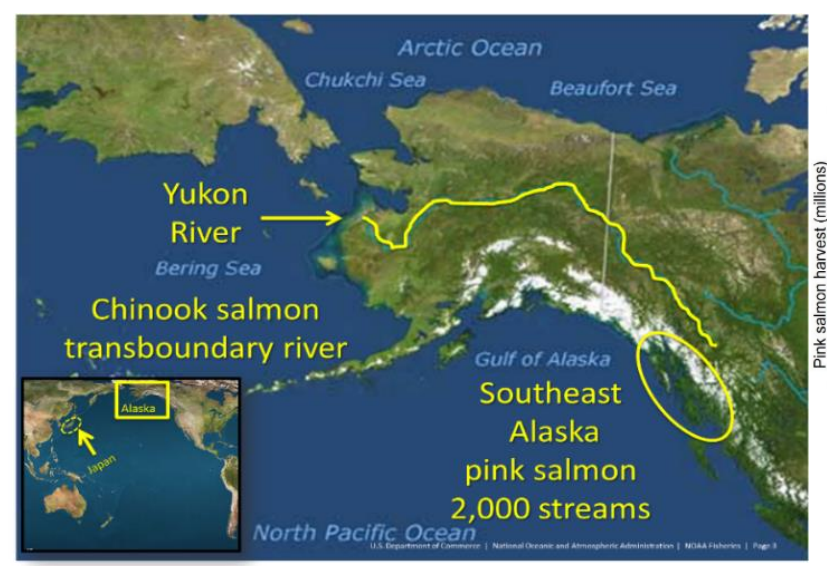

Fig. 1. Two regions in Alaska where salmon forecast models were performed: pink salmon harvest in Southeast Alaska and upper Yukon Chinook salmon return strength in the Yukon River in Western Alaska.

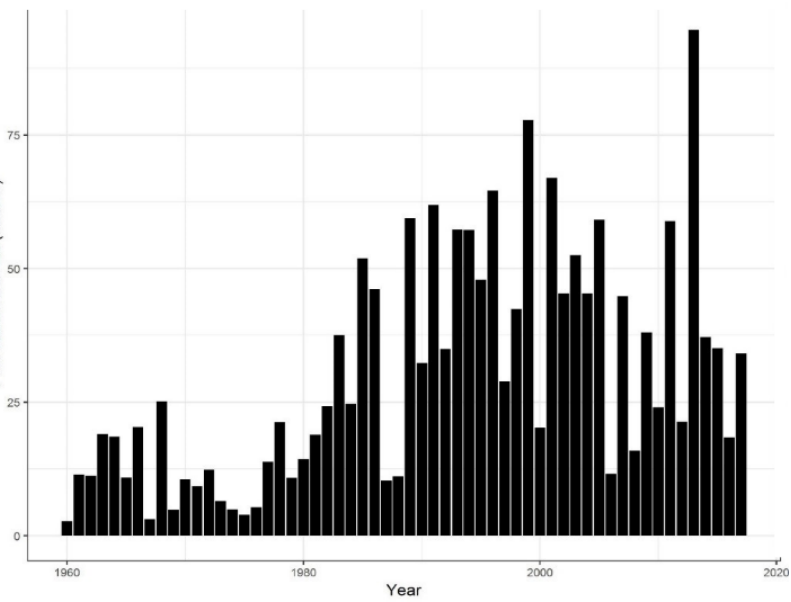

Fig. 2. Variability of commercial pink salmon harvest in Southeast Alaska since 1960. Over this period harvests have ranged from 2-95 $\mathrm{M}$ fish, with the overall production composition of $97 \%$ wild stock based.

The presentation explores the specifics of each example by following a "road map" of steps to connect ecosystem metrics to response variables in order to develop products useful to salmon managers and stakeholders. The roadmap steps are: 1) Identify a problem in need of a solution with climate-driven ecosystem services; 2) Understand and define processes and relationships between climate, fish production and behavior, and fishery performance; 3) Develop research products based on the relationships; and 4) Operationalize research products through timely, dependable delivery to managers and stakeholders.

For the pink salmon fisheries in SEAK, the problem (Step 1) was identified as the high degree of uncertainty introduced into planning for harvesting, processing, and marketing by the high level of variability in annual pink salmon abundances (Fig 2). Motivation to find a solution was added by the large economic value of the fishery with an annual ex-vessel value 10 year average of $\sim 44$ million, and the importance of pink salmon to the ecosystem. The mechanism by which climate drives fish behavior (e.g., ocean distribution of juvenile abundance) and subsequently, fishery performance, has historically been poorly understood. We hypothesized (Step 2) however, that mortality of pink salmon during their early marine phase is high, variable, and a primary driver of year class strength. Thus, after this critical early period, surveys that assess juveniles during their seaward migration were expected to be more effective predictors of adult returns (i.e., year class strength). However, ocean conditions during the subsequent (first) winter of ocean residence could still demonstrate impacts. Through research (Step 3) the result was readily identified as an accurate and reasonably precise forecast of annual harvest (Fig. 3). The pink salmon harvest forecast model is based on a juvenile abundance index (from surface trawl surveys) adjusted for 
temperature (Fig 4). Information on juvenile growth condition, diet, prey availability, and climate indices are included as ecosystem considerations of the forecast (Orsi et. al. 2017). The research was operationalized (Step 4) through timely communication with the Alaska Department of Fish \& Game (ADFG) so the survey information could be incorporated into their forecasts (10 months prior to the fishery). As a final step in operationalizing the forecast, the pre-season pink salmon forecast was presented to resource stakeholders at the SEAK Purse Seine Task Force Meeting (seven months prior to fishery) and simultaneously communicated via a forecast webpage.
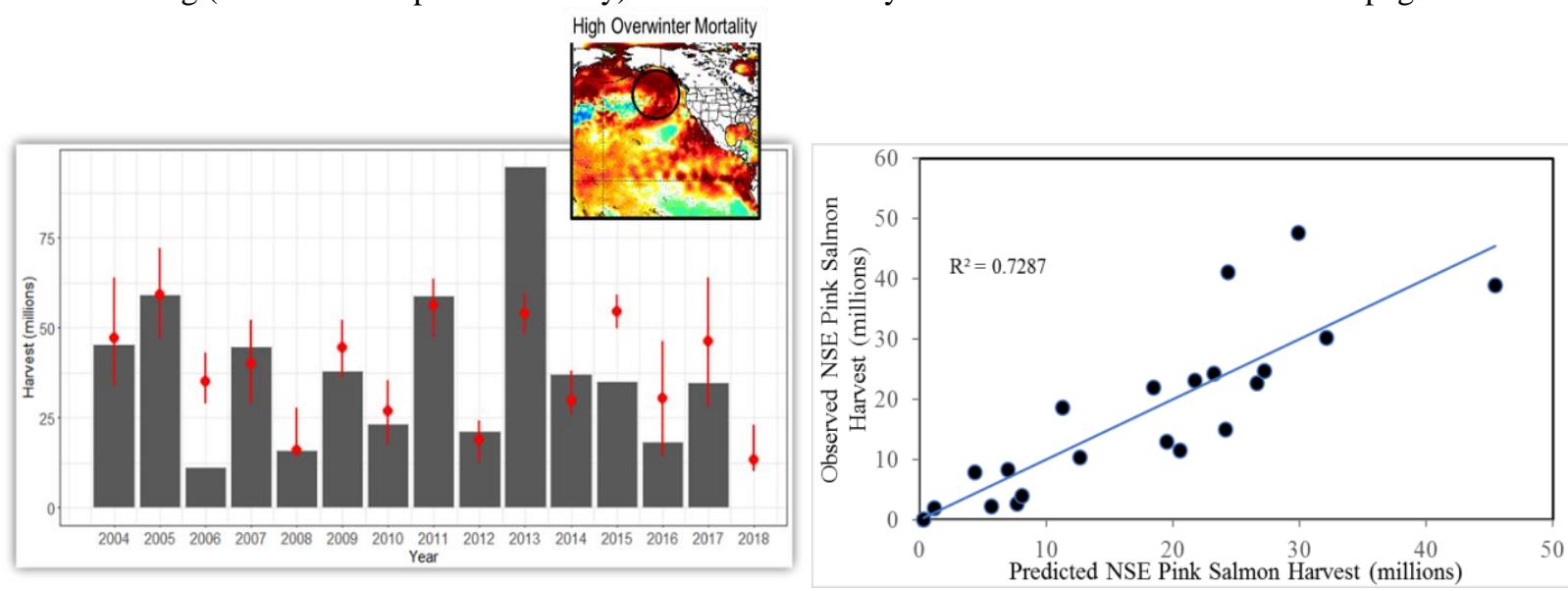

Fig. 3. Pre-season harvest forecast of pink salmon to Southeast Alaska (circles) with $80 \%$ confidence intervals and the actual harvests seven months later (bars). 2014-2016 had anomalous warm water

Fig. 4. Southeast Alaska Pink Salmon Harvest Forecast Model (CPUE +Temperature). summer and winter temperatures.

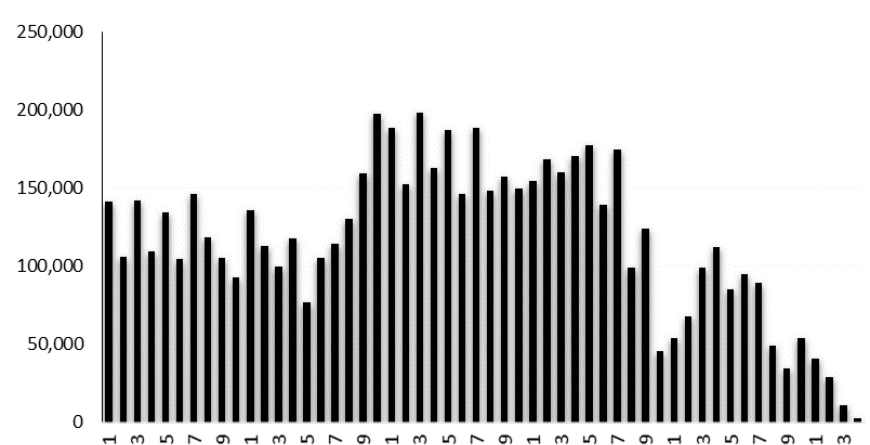

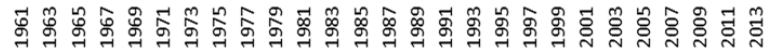

Fig. 5. Yukon River Chinook salmon harvest.

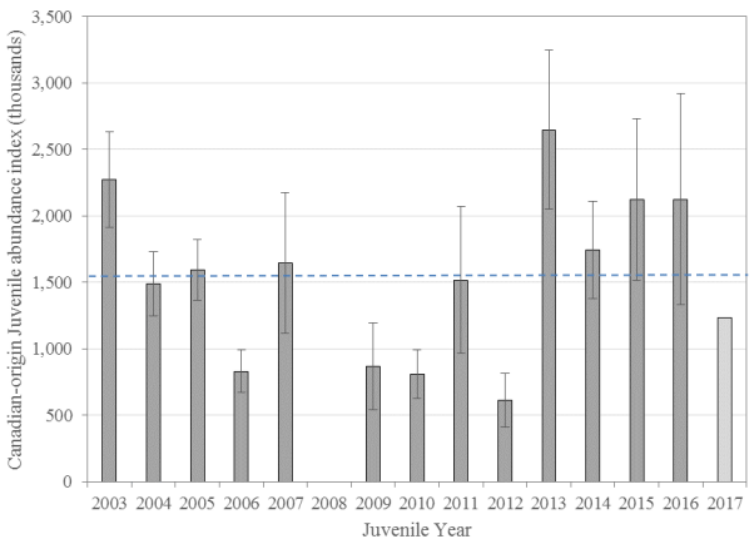

Fig. 6. Canadian-origin juvenile index in the northern Bering Sea (average cv of $23 \%$ ).

For Yukon River Chinook salmon, the problem (Step 1) was identified as large inter-annual fluctuations in run strength and subsequently, harvest (Fig 5). A sense of urgency in finding a solution has been fueled by a decline in abundance to levels low enough to precipitate a Federal disaster declaration for the fisheries. Further urgency is added by the presence of an international treaty with Canada that requires U.S. fisheries to pass a minimum number of adult Upper Yukon (Canadian-origin) Chinook across the Canadian border each year which has become difficult with abundance declines. As with southeast Alaska pink salmon, a lack of mechanistic understanding (Step 2) of relationships between climate, fish behavior (juvenile abundance and ocean distribution) and fishery performance (adult production) for Yukon Chinook was addressed by using the hypothesis that mortality during Chinook salmon's early marine life history is 
high, variable, and affects year class strength. After this critical early period, surveys of juvenile abundance in the northern Bering Sea can inform predictions of year class strength. However, ocean conditions can also impact fish during the first winter of ocean residence and drive variability in forecasts. Using research (Step 3), a time series of juvenile Chinook salmon abundance was constructed for the Canadian-origin (Upper Yukon) stock group for late-summer (typically during the month of September) pelagic rope trawl surveys in the northern Bering Sea, (BASIS) from 2003-2017. Abundance is estimated from trawl catch-per-unit-effort data, genetic stock composition, and mixed layer depth. Juvenile Chinook salmon abundance estimates for the Canadian-origin stock group have ranged from 0.6 million to 2.6 million juveniles with an overall average of 1.5 million juvenile Chinook salmon from 2003 to 2017 (Fig. 6). The Canadian-origin juvenile abundance index is significantly correlated with adult Canadian-origin returns (Fig. 7) which facilitates a forecast of future returns of the Canadian-origin stock group to the Yukon River (Fig 8). To operationalize the research (Step 4) this forecast was presented to the Yukon River stakeholders through the Yukon River Joint Technical Committee.

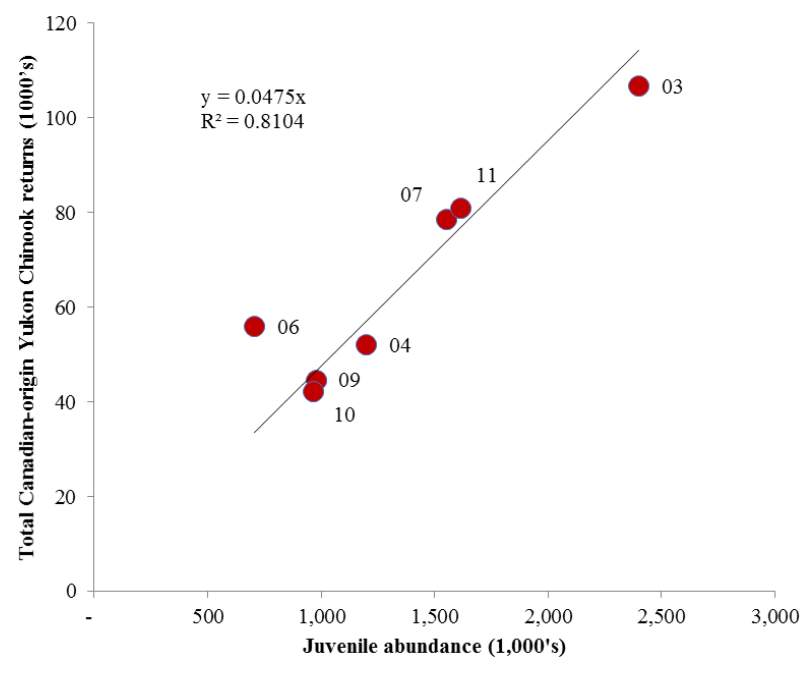

Fig. 7. Relationship of Canadian-origin juvenile index and adult returns.

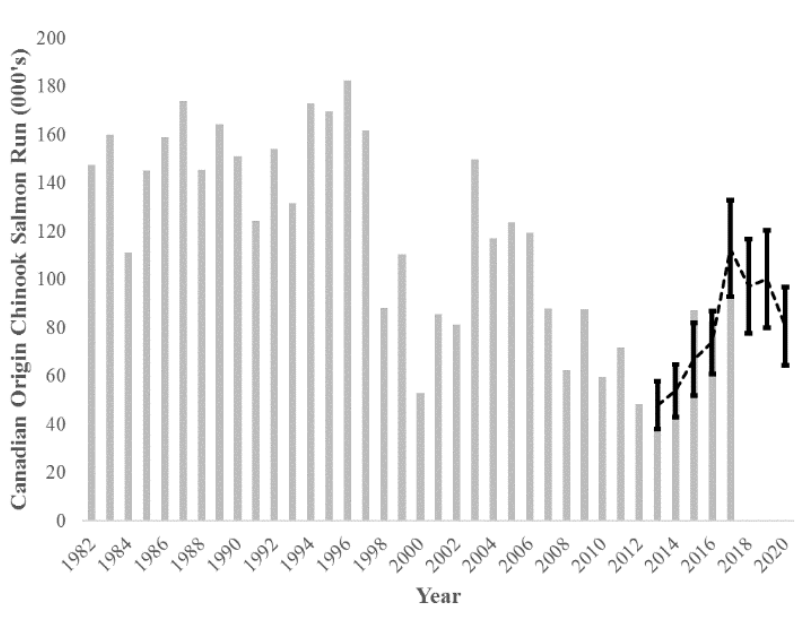

Fig. 8. Accuracy of Canadian-origin juvenile index forecast to adult returns of the last three years and future predictions.

Note: The views expressed in this abstract are those of the author and do not necessarily represent those of National Oceanic and Atmospheric Administration (NOAA).

\section{REFERENCES}

Orsi, J.A., E.A. Fergusson, A.C. Wertheimer, E.V. Farley, and P.R. Mundy. 2017. Forecasting pink salmon production in Southeast Alaska using ecosystem indicators in times of climate change. N. Pac. Anadr. Fish Comm. Bull. 6: 483-499. (Available at http://www.npafc.org) 